
\title{
$\begin{array}{ll}\text { Research Square } & \text { They should not be considered conclusive, used to inform clinical practice, } \\ \text { or referenced by the media as validated information. }\end{array}$
}

\section{Impact of Gervital Against Histopathological, Ultrastructural, and Biochemical Alterations Caused by Methotrexate or Azathioprine in Albino Rats Testis}

\author{
Manal Abdul-Hamid \\ Beni Suef University Faculty of Science \\ Eman Salah Abdel-Reheim \\ Beni Suef University Faculty of Science \\ Walaa Hegazy \\ Beni Suef University \\ Ahmed Allam ( $\nabla$ ahmed.aliahmed@science.bsu.edu.eg ) \\ Beni Suef University https://orcid.org/0000-0003-0702-8025 \\ Sarah I. Othman \\ Princess Nourah bint Abdulrahman University \\ Haifa A Alqhtani \\ Princess Nourah bint Abdulrahman University \\ Samraa Hussein Abdel-Kawi \\ Beni Suef University Faculty of Medicine
}

\section{Research Article}

Keywords: Methotrexate, Azathioprine, Gervital, Oxidative stress, Testis, Histopathology \& Ultrastructural

Posted Date: February 9th, 2022

DOI: https://doi.org/10.21203/rs.3.rs-1235565/v1

License: (c) This work is licensed under a Creative Commons Attribution 4.0 International License. Read Full License 


\section{Abstract}

Methotrexate (MTX) and azathioprine (AZA) are chemotherapeutic, immunosuppressive, cytotoxic drugs with reported adverse impacts such as oxidative damage to testis. This study aims to scrutinize the potential effect of grape seed extract (GSE; gervital) to prevent testicular damage propelled by MTX and AZA. Rats were separated into six groups: Group I, normal control group; Group II, GSE (150 mg/kg/day); Group III, MTX (8 mg/kg/week). Group IV, AZA (15 mg/kg/day). Group V, GSE (150 mg/kg/day) + MTX (8 mg/kg /week); Group VI, GSE (150 mg/kg/day) + AZA (15 $\mathrm{mg} / \mathrm{kg} /$ day). All rats were sacrificed, blood samples were obtained for testosterone analysis and testis was removed for histological, ultrastructural studies and oxidation measurements. A reduction in body and testes relative weight, along with a significant decrease in testosterone was observed. Histopathological, ultrastructural alterations induced by MTX or AZA include scanty spermatozoa, sloughing, marked reduction of spermatogonia cells, and pyknosis of some nuclei. Significant oxidative stress (OS) manifested by reduced glutathione (GSH) level, catalase (CAT) and superoxide dismutase (SOD) as well as increase in malondialdehyde (MDA) levels. GSE administration showed an ameliorative effect on testosterone, histopathological and ultrastructural changes. GSE treatment also suppressed the increases in MDA levels and the decrease in GSH level, CAT, and SOD activities. Conclusion, our findings confirmed that GSE is an effective antioxidant that prevent and protect testis from the histopathological and ultrastructural damages induced by MTX and AZA. So, GSE is a promising candidate for future use to minimize and alleviate MTX and AZA risks

\section{Introduction}

Chemotherapy is the utilize of chemical agents to suppress or kill proliferating cancer cells by several mechanisms, including cell membrane damage, intercalation into DNA, inhibition of DNA replication, or free radical generation. The target of anticancer drugs is not only the tumor but also other cells, thus causing the same deterioration for both defective and normal cells (Granados-Principal et al. 2010).

Methotrexate (MTX) and Azathioprine (AZA) are classified as cytotoxic drugs, utilized in the treatment of cancer with reported devastating impacts such as oxidative damages to the DNA/RNA and body organs (Elelaimy et al. 2012). AZA and MTX increase oxidative stress (OS) in testicular tissues and decrease testosterone hormones. Both have a destructive effect on the functions and morphology of the testes in adult Wister rats thus they disrupt seminiferous tubules (Akinlolu et al. 2014).

MTX is vastly utilized as a cytotoxic chemotherapeutic agent treatment of certain cancers (Zhang et al. 2022). MTX causes several side effects if used for long or short periods (Alahmadi and Abduljawad 2021). Numerous studies have documented the remarkable role of apoptotic cell death driven by MTX-propelled testicular impairment (Maremanda \& Jena 2017). MTX causes a decrease in the diameter of the lumen of the seminiferous tubule, and the degeneration and shedding of germ cells (Liu et al. 2015).

AZA is a cytotoxic immunomodulatory drug that is commonly used to treat inflammatory bowel disease, autoimmune disorders, organ transplant rejection, and cancer ( Reggio et al. 2019;Bergasa 2022)). AZA leads to interstitial spaces to be poorly defined, scanty spermatogenic cells and spermatozoa, disrupted, and shrunken seminiferous tubules (Shaikh et al. 2020b).

Antioxidants are considered the first line of defense against free radical destruction and are perfect for keeping ideal health and well-being. They play an animated role against reactive oxygen species (ROS) in the body's defense system (Hasanuzzaman et al. 2020). Grape (Vitis vinifera) is one of the greatest frequently consumed fruits in the world and the world's major fruit crop (Raja et al. 2020).

Grape seed extract (GSE); gervical is a potent antioxidant compound because it can surmount superoxide radicals in living cells and the main component of it is proanthocyanidins. It conserves cells from dangerous diseases thus it is considered as anti-diabetic, anti-tumor, anti-microbial, anti-aging and anti-inflammation (Kwatra 2020). This study aimed to scrutinize the potential role of GSE to prevent testicular damage propelled by MTX or AZA. Also, to clarify the ultrastructural changes induced by azathioprine, since little is known about it in the previous studies.

\section{Materials And Methods}

\subsection{Drug and treatment}

MTX was obtained from Orion Corporation Finland imported by SM; each tablet contained 2.5 mg. AZA, produced by Rpg Life Science Limited in India, and imported by the international trading office; each tablet contained $50 \mathrm{mg}$. GSE is proanthocyanidins obtained from the Enshas-Sharkeya (Egypt) Pharmaceutical and Medicinal Plants Arab Company (MEPACO -MEDIFOOD), each capsule contained 150 mg.

\subsection{Animals and experimental design}

A total of thirty-six Wistar rats; 140-200 g, aged 6-8 weeks old, were collected from Nahda University Animal House Facility Center. All experimental rats were housed and maintained in a clean rodent room and well ventilated under standard conditions of temperature and humidity, room temperature $\left(25 \pm 5^{\circ} \mathrm{C}\right)$ with 12 -h dark/light cycles and were received free access to a standard diet of pellets and tap water. They were saved under observation for 15 days before the experiment started to rule out any intercurrent infections. Animals received human care in 
compliance with the recommendations of the Committee for the control Purpose, Care animals follow the European Community Directive (86/609 / EEC Edition 8). This has already been approved Committee of Zoology, Beni-Suef University, Egypt. IACUC (permit number BSU/FS/2018/1).

\subsection{Animal grouping}

Rats were separated into six groups ( $n=6)$. Group I, normal control group. Group II (GSE); animals were orally given GSE (150 mg/kg body weight /day) dissolved in distilled water according to previous research (Bagchi et al. 2001). Group III (MTX); animals received an oral dose of MTX (8 $\mathrm{mg} / \mathrm{kg}$ body weight /week) dissolved in 5\% tween 80 and saline once a week (Akinlolu et al. 2014). Group IV (AZA); animals received an oral daily dose of the solutions of AZA ( $15 \mathrm{mg} / \mathrm{kg}$ body weight/day) were kept in saline containing $5 \%$ Tween 80 acquiesced with previous research (Akinlolu et al. 2014) Group V (GSE +MTX); rats were treated with a dose of GSE then followed after $2 \mathrm{~h}$ by an oral dose of MTX. Group VI (GSE +AZA); animals were administered with a dose of GSE then followed after $2 \mathrm{~h}$ by an oral dose of AZA.

\subsection{Sample collection and the biochemical estimation}

Rats were sacrificed after 35 days of the experiment under light diethyl ether anesthesia. Each rat was examined weekly for bodyweight investigation. With the aid of a capillary tube, blood samples were taken from the retro-orbital venous plexus into serum tubes (Kumar et al. 2011). Sera were separated by centrifugation for testosterone determination by the method of Maruyama et al. (1987).

\subsection{Tissue homogenate preparation and oxidative stress-related markers assay}

The testes were rapidly expelled from the surrounding tissues and weighed. Testis homogenate $25 \%$ in isotonic ice-cooled normal saline. The resulting homogenate was centrifuged for $15 \mathrm{mins}$ at a speed of $10.000 \mathrm{rmp}$. At $-20^{\circ} \mathrm{C}$, the supernatant was preserved before analysis. The testicular homogenate was used for malondialdehyde (MDA) estimation according to Altintas et al. (2014). Testicular superoxide dismutase (SOD) and catalase (CAT) activities (Marklund \& Marklund 1974); (Claiborne 1985) were measured respectively. Glutathione (GSH) was calculated by using the method of previous research (Sedlak \& Lindsay 1968).

\subsection{Histological examination}

Testis tissues were cut into $0.5 \mathrm{~cm}^{3}$ small pieces and then fixed for $24 \mathrm{~h}$ in $10 \%$ neutral formalin buffer. Testis specimens were cleaned to remove the residual fixative and then dehydrated for 45 minutes each in ascending grades of ethanol, then for 30 minutes each in two levels of absolute ethyl alcohol. This was followed by clearance of 30 minutes each in two xylene changes. The tissues were then soaked for three hours at $60^{\circ} \mathrm{C}$ with paraplast plus (three changes) and then embedded in paraplast plus. For histopathological tests, sections 4 to $5 \mu \mathrm{m}$ thick were equipped with a microtome and stained with Hematoxylin and eosin (H\&E) (Bancroft \& Gamble 2008).

\subsection{Ultrastructural examination}

Testis specimens were cut into small pieces measuring about $1 \mathrm{~mm}^{3}$ and immediately fixed for $18-24$ hours in fresh $3 \%$ glutaraldehydeformaldehyde at $4{ }^{\circ} \mathrm{C}$. The specimens were then washed in a phosphate buffer $(\mathrm{pH} 7.4)$ and then set for one hour at $4{ }^{\circ} \mathrm{C}$ in isotonic $1 \%$ osmium tetroxide. (Bain \& Mercer 1966). A Series of alcohol dehydration was done. The specimens were then transmitted through a propylene oxide solution 2 times in 10 minutes each. Embedding of the specimens in Epon epoxy resin started by infiltrating the specimens in the propylene oxideresin mixture overnight. The specimens were transferred to fresh-resin capsules for polymerization to obtain hard blocks. Sections of Semithin were cut by ultracut Reichert-Jung ultramicrotome from these blocks with the aid of glass knives, stained with toluidine blue stain. According to prior research. (Bozzola \& Russell 1999) ultrathin sections were then prepared and stained with uranyl acetate and lead citrate, and examined with a Joel CX 100 transmission electron microscope operating at an accelerating voltage of $60 \mathrm{KV}$.

\subsection{Statistical analysis}

The Statistical Package for the Social Sciences (SPSS, version 20.0 for WINDOWS; SPSS, Chicago, IL). The results were elucidated as the mean \pm standard error and all statistical comparisons were calculated using one-way ANOVA test (Rao et al. 1985) followed by Duncan's multiple range test analysis values. The significant difference is counted at $P$-value $<0.05$.

\section{Results}

\subsection{Body weight}

MTX and AZA therapy affected the percentage of change between the two body weights, where the rats suffered from a marked decrease $(P<0.05)$ as compared to the control and GSE groups. While GSE showed maintenance of body weight in MTX plus GSE group (Fig. 1).

\subsection{Testes relative weight}

MTX and AZA therapy affected relative testis weight, where the rats suffered from a marked decrease $(P<0.05)$ in testis relative weight when compared to the control and GSE groups. While co-administration of MTX with GSE or AZA with GSE conserves the decrease in testis relative weight (Fig. 2). 


\subsection{Testosterone determination}

A significant decrease in testosterone $(\mathrm{P}<0.05)$ in MTX and AZA groups in comparison to the control and GSE groups. GSE treatment produced a potential amelioration of testosterone for both MTX and AZA treated groups (Fig. 3).

\subsection{Testis antioxidant parameters and oxidative stress}

Lipid peroxidation (LP), articulated as MDA concentration was measured as a biomarker of testis OS state. It is demonstrated a significant increase in MTX and AZA treated groups when compared to control and GSE treated ones. GSE treatment agent produced a potential improvement of the LP level for both MTX and AZA treated groups. Concerning the enzymatic and non-enzymatic antioxidant defense system, CAT, SOD, and GSH all revealed a noticeable reduction in MTX and AZA groups $(P<0.05)$. On the other hand, GSE improved the activities of these antioxidant enzymes and increased GSH levels in the treated groups (Table 1).

Table 1

The potential preventive effect of GSE against MTX and AZA induced changes in MDA level, CAT, SOD activity and GSH concentration in testis tissue of all experimental groups.

\begin{tabular}{|c|c|c|c|c|}
\hline Parameters & $\begin{array}{l}\text { MDA } \\
\text { (nmol/g tissue) }\end{array}$ & $\begin{array}{l}\text { CAT } \\
\left(\mathrm{K} \times 10^{2}\right)\end{array}$ & $\begin{array}{l}\text { (GSH) } \\
\text { (nmol/g tissue) }\end{array}$ & $\begin{array}{l}\text { (SOD) } \\
\text { (U/g tissue) }\end{array}$ \\
\hline Control & $22.861 \pm 1.9^{d}$ & $107.60 \pm 2.8^{c}$ & $20.84 \pm 0.93^{\mathrm{cd}}$ & $121.97 \pm 2.2^{c}$ \\
\hline GSE & $20.83 \pm 1.05^{d}$ & $112.49 \pm 5^{c}$ & $22.14 \pm 0.82^{d}$ & $132.34 \pm 1.9^{c}$ \\
\hline MTX & $78.33 \pm 2.4^{a}$ & $51.93 \pm 2^{\mathrm{a}}$ & $9.29 \pm 1.3^{\mathrm{a}}$ & $59.87 \pm 3.1^{a}$ \\
\hline AZA & $86.55 \pm 1.7^{a}$ & $41.40 \pm 3.7^{a}$ & $6.97 \pm 1.2^{\mathrm{a}}$ & $53.52 \pm 1.3^{a}$ \\
\hline GSE+MTX & $40.95 \pm 2.1^{c}$ & $77.75 \pm 1.8^{\mathrm{b}}$ & $16.78 \pm 0.34^{\mathrm{cb}}$ & $94.68 \pm 1.3^{\mathrm{b}}$ \\
\hline $\mathrm{GSE}+\mathrm{AZA}$ & $56.4 \pm 5^{b}$ & $71.44 \pm 3^{b}$ & $14.95 \pm 0.61^{b}$ & $84.03 \pm 2.5^{\mathrm{b}}$ \\
\hline \multicolumn{5}{|c|}{ Each value represents the Mean \pm standard error (SE) } \\
\hline \multicolumn{5}{|c|}{ Values with different superscript letters are considered significantly different $(P<0.05)$} \\
\hline \multicolumn{5}{|c|}{ Values with letter $(a)$ is considered significantly different $(P<0.05)$} \\
\hline
\end{tabular}

\subsection{Histopathological changes}

Examination of testicular tissue of both control and GSE-treated animals revealed normal seminiferous tubules with active spermatogenesis. Spermatogonia and triangular Sertoli cell resting upon the basement membrane. Leydig cell and cluster of spermatozoa were seen in lumen. Primary spermatocytes were recognized by their large nuclei containing coarse clumps of chromatin, and spermatids appeared with rounded nuclei in control (Fig. 4a and b) and GSE (Fig. 4c and d).

Animals treated with MTX showed severe degenerated and variable-sized seminiferous tubules, where many tubules appeared with a marked decrease in the spermatogenic cells and few or no sperms. Detachment of spermatogenic cells from the basal lamina and vacuolated cytoplasm was observed. There was sloughing of spermatogenic cells into the lumen of seminiferous tubules (Fig. 4e).

Animals treated with AZA revealed degenerated seminiferous tubules with ruptured basement membrane were observed. Notice the detachment of spermatogenic cells from the basal lamina and vacuolated cytoplasm. The reduction of spermatogenic cells and pyknosis of some nuclei were also seen (Fig. 4f).

Examination of testes of animals treated with GSE plus MTX revealed approximate recovery of seminiferous tubules amelioration of spermatogenic cells, and spermatozoa except few vacuoles were observed. Normal Leydig cells were seen in the interstitial tissue (Fig. $4 \mathrm{~g}$ ). Examination of testes of animals treated with GSE and AZA showed improvement of spermatogenesis, nearly normal structure in most seminiferous tubules. Compact spermatogenic layers with few degenerative germ cells and normal Leydig cells were seen (Fig. 4h).

\subsection{Ultrastructural changes}

The electron microscopic examination of the control testis revealed the spermatogonia rested on the basement membrane, myoid cell, the Sertoli cell had a triangular nucleus, primary spermatocyte with mitochondria, and large spherical nucleus (Fig. 5a). There was a Rounded Spermatid with spherical nuclei, acrosomal cap, and peripherally located mitochondria were observed (Fig. 5b). In addition to lumen contains normal 
spermatozoan at the midpiece and tail region (Fig. 5c). Normal interstitial tissue containing Leydig cell with a large nucleus, thin rim of chromatin, prominent nucleolus, lipid droplet, and capillaries (Fig. 5d).

The ultrastructure observation of testes of animals administered with MTX revealed many vacuoles and vacuolated mitochondria in spermatogonia, Sertoli cell, and primary spermatocyte. Presence of some lysosome in the Sertoli cells and spermatogonia (Fig. 6a). Distorted spermatid with marked cytoplasmic vacuolation and rarified cytoplasm surrounded by a large lytiareashe presence of some lysosome and some degenerated mitochondria was observed (Fig. 6b). A marked decrease in the number of sperms in the lumen of the seminiferous tubule (Fig. 6c). Abnormal interstitial tissue with degenerated Leydig cell with an irregular nucleus having a thick rim of heterochromatin, few lipids drop and dilated smooth endoplasmic reticulum were also seen (Fig. 6d).

The ultrastructure observation of testes of animals administered with AZA showed many vacuoles in both Sertoli cells and spermatogonia cells and an overall decrease in cytoplasmic ground substance (Fig. 7a). Thick ruptured irregular basement membrane, vacuolated primary spermatocyte, and severe degenerated Sertoli cells with many vacuoles and some lysosomes were detected (Fig. 7b). There was distorted and vacuolated early spermatid. Notice the dissolution of some cells (Fig. 7c). Degenerated vacuolated spermatid and dissolution of some cells were observed (Fig. 7d). In addition to degenerated Leydig cell. Notice the irregular nuclear envelope with dark clumps of heterochromatin adjacent to the nuclear membrane and notice presence of few lysosomes (Fig. 7e).

The ultrastructure observation of testes of animals administered with GSE and MTX showed amelioration in the structure of spermatogonium, Sertoli cell and primary spermatocyte except few degenerated mitochondrial (Fig. 8a). Normal spermatid appeared with a rounded nucleus and peripherally located mitochondria except a few cytoplasmic vacuolations and a few lysosomes (Fig. 8b). Lumen with marked recovery in transverse sections of normal sperms at mid piece and tail region (Fig. 8c). Leydig cells with a large nucleus, smooth endoplasmic reticulum, lipid droplets, and blood capillaries were seen (Fig. 8d).

The ultrastructure observation of testes of animals administered with GSE and AZA revealed a slightly normal basement membrane, improvement in the structure of cells except vacuolation in Sertoli cell, spermatogonia, primary spermatocyte, and spermatid which with a rounded nucleus and normal acrosomal cap (Fig. 9a). In addition, around spermatid appeared with an acrosomal cap, peripherally located mitochondria, and few cytoplasmic vacuolations (Fig. 9b). Round spermatid and a moderate number of cross-sections at the midpiece and tail region of sperms were seen in the lumen (Fig. 9c). Interstitial tissue and Leydig cell with a normal nucleus and a moderate number of lipid droplets were observed (Fig. 9d).

\section{Discussion}

Chemotherapy drugs cause testicular apoptosis, which is an obvious side effect (Abu-Risha et al. 2022). GSE is a powerful antioxidant as demonstrated by a previous studies of (Abdul-Hamid, et al. 2018; Priyadarshi et al. 2022) when comparing GSE with Ginkgo biloba to reduce hepatotoxicity induced by the antidysrhythmic drug. The present study showed a remarkable reduction in both body weight and testes relative weight of MTX treated rats when compared to a control group and the GSE group. Similar results were observed by Arisha (2017) who demonstrated that the reduction may reflect direct toxicity, low feed intake, and water intake. Animals showed diarrhea, the probable reason for these could be the corrosive and irritating impact of MTX on gastrointestinal mucosa was reported by Patel et al. (2014). This study manifested decrease in both body weight and testes relative weight with AZA, this was also reported by recent Shaikh et al. (2020a). Body weight and testes relative weight returned near to normality after treatment with GSE, this agrees with previously conducted study of Hajizadeh et al. (2016) who found that rats treated with GSE after treatment with fluoxetine or doxorubicin significantly increased body weight. Testes are the most serious goal organs for OS as a result of their high content of polyunsaturated membrane lipid (Belhan et al. 2017). An imbalance between the formation and elimination of free radicals can produce a pathological condition (Bhattacharya 2015). OS can worsen biological molecules, such as lipids, proteins, polysaccharides, and DNA (Yüncü et al. 2019). The present study showed disruption in testis oxidation with MTX or AZA manifested by increase MDA levels and a decrease in GSH production and reduced activity of both CAT and SOD. This is in accordance with Akinlolu et al. (2014). In testicular development and spermatogenesis, SOD plays a critical function. Changes in this enzyme can cause sperm development to stop and testicular function to be affected (Prahalathan et al. 2004). In our study rats treated with GSE plus MTX or rats treated with GSE plus AZA revealed a decrease in MDA levels and an increase in GSH, CAT, and SOD levels in accordance with Hui et al. (2020) who approved the radical scavenger activity of GSE. This study revealed decrease in testosterone levels in MTX or AZA-treated group. The production and secretion of testosterone drop due to the loss of sexual cells, Sertoli cell damage, atrophy of interstitial cells and OS decreases the anabolic effect of testosterone (Ramadan et al. 2018). Treatment with GSE plus MTX restored the activity of serum testosterone level to normal, this results in accordance with Arisha (2017) who found that treatment with GSE after that MTX administration restored the activity of serum testosterone level to normal. The present study found treatment with GSE with AZA restored the activity of serum testosterone level to normal. Similarly, Mohamadpour et al. (2020) reported that GSE was enabled of returning the activity of serum testosterone to normal level. The present light microscopic examination revealed that the testis of MTX or AZA demonstrated histopathological changes in the seminiferous tubules when compared with the control group and GSE group. This agreed with the prior results of Akinlolu, et al. (2014). In the present study, MTX - treated group showed degenerated and variable-sized seminiferous tubules with a marked decrease in spermatogenic cells. A similar result Shrestha et al. (2007), indicated that the size of seminiferous tubule cellular contents changed significantly that may be because of primary spermatocytes and spermatids unsuccessful to replicate DNA

Page 5/12 
because inhibition of dihydrofolate reductase, an important enzyme essential for normal DNA synthesis. This study manifested many tubules appeared with damage to the structure of germ cells. Moreover, Ateşşahin et al. (2006) manifested that damage to the structure of germ cells caused by OS. The current AZA-treated group revealed degenerated seminiferous tubules, marked decrease in the spermatogenic cells, pyknotic nuclei, and vacuolated cytoplasm. The cytoplasmic vacuolation may be due to Sertoli cell damage, where Sertoli cells control the spermatogenic process as explained by recent research by Abdelbaky et al. (2020). The present ultrastructural study of the MTX group revealed several extreme changes in spermatogonia and Sertoli cells. Richburg (2000), manifested that when Sertoli cell numbers diminish, the number of germinal cells declines intensively. The present study also revealed cytoplasmic vacuolations and marked decreasing of sperm number in the lumen of the seminiferous tubule. Reduced relative testicular weight along with damage to the sperm DNA and sperm count (Padmanabhan et al. 2009) and spermatozoa have been highly susceptible to LP resulted from ROS due to the high contact polyunsaturated fatty acids as manifested previously by Alvarez et al. (1987). The current ultrastructural study of the AZA group revealed a germ cell with pyknotic nuclei and vacuolated cytoplasm. Degenerated Sertoli cells and spermatogonia cells with many vacuoles. This results in agreement with Karawya and El-Nahas (2006) who demonstrated the decrease in the testis weight is indirectly indicative of the effect on spermatogenesis. The current study also revealed a marked decrease in the number of sperms in the lumen. Similar results were observed by Onanuga et al. (2014). The present light microscopic examination and ultrastructural study of testis treated with GSE plus MTX and testis treated with GSE plus AZA showed nearly normal structure in most seminiferous tubules, improvement of spermatogenic cells, Sertoli cell, primary spermatocyte except few degenerated mitochondrial. These results are similar to several studies conducted on the use of antioxidant substances to reduce these side effects of MTX (Yucel et al. 2017; Yüncü et al. 2019). Moreover, Arisha (2017) conducted that GSE improves the histological and ultrastructural of testes toxicity induced by MTX. GSE prevents AZA toxicity in rats (El-Ashmawy et al. 2010). The current study agreed with a similar study that showed that GSE possesses cytoprotective ultrastructure and antitoxic effects in hepatocytes during $\mathrm{CCL}_{4}$ intoxication (Hovnanyan et al. 2014).

\section{Conclusion}

The present study determined that GSE had preventive effects against MTX or AZA Prompted testicular damage that was confirmed through histological, ultrastructure and biochemical studies. The preventive effect of GSE may be attributed to its antioxidant potential against free radicals. Our study revealed marked amelioration after treatment with GSE on toxicity induced by MTX and AZA, but there were slight improvements in MTX-treated group compared to AZA-treated group.

\section{Declarations}

\section{Ethics approval and consent to participate}

All experimental procedures were performed in accordance with recommendations, instructions, and guidelines of the regulatory committee, Animal Care followed the Direction of the European Community (86/609 / EEC Edition 8). This has been accepted by the Committee of Zoology, Beni-Suef University, Egypt. The IACUC Permit Number (BSU/FS/2018/1).

\section{Consent for publication}

Not applicable

\section{Authors contributions}

M.A., and E.S.A. and S.H.A., have contributed in suggesting design of the work, preparation and analysis of the results, and also thanks A.A. and S.I.O., and H.A. for interpretation of data and discussion. In addition, W.H. has performed the experiments, analyzed the data and drafted the manuscript. All authors are in agreement with the contents of the manuscript. All authors read and approved the final manuscript.

\section{Acknowledgments}

The authors acknowledge Princess Nourah bint Abdulrahman University Researchers Supporting Project number (PNURSP2022R5), Princess Nourah bint Abdulrahman University, Riyadh, Saudi Arabia

\section{Funding}

The authors thank Princess Nourah bint Abdulrahman University Researchers Supporting Project number (PNURSP2022R5), Princess Nourah bint Abdulrahman University, Riyadh, Saudi Arabia

\section{Competing interests}

The authors declare that they have no competing interests. 
The authors confirmed that All data generated or analyzed during this study are included in this published article.

\section{References}

1. Abdelbaky NW, Abdelazem AZ, Hashem KS (2020) Thymoquinone attenuates 6-mercaptopurine induced testicular toxicity in albino rats: possible mechanisms are involved. Adv Anim Vet Sci 8(6):653-660. http://dx.doi.org/10.17582/journal.aavs/2020/8.6.653.660

2. Abdul-Hamid M, Galaly SR, Mahmoud H et al (2018) The protective effect of grape seed and Ginkgo biloba against hepatotoxicity induced by the antidysrhythmic drug "amiodarone" in male albino rats. BJBAS 7(2):223-230. https://www.sciencedirect.com/science/article/pii/S2314853517303116

3. Abu-Risha SE, Mousa MA, Elsisi AE (2022) Protective role of irbesartan against cyclophosphamide-induced testicular damage in rats via upregulating PPAR-y signaling and ameliorating NF-KB/NLRP3/IL-18 inflammatory axis. Life Sci 289:120218. https://www.sciencedirect.com/science/article/pii/S0024320521012054

4. Akinlolu A, Akinola O, Khobe P et al (2014) Azathioprine and methotrexate impaired the morphology and functions of the testes in adult wistar rats. J Morphol Sci 31(02):075-081. https://www.thieme-connect.com/products/ejournals/pdf/10.4322/jms.057513.pdf

5. Alahmadi AA, Eman A, Abduljawad (2021) Equisetum arvense L. Extract Ameliorates Oxidative Stress, Inflammation and Testicular Injury Induced by Methotrexate in Male Rats. J Pharm Res Int 101-114. https://www.thieme-connect.com/products/ejournals/abstract/ 10.4322/jms.057513

6. Altintas R, Polat A, Parlakpinar H et al (2014) The effect of melatonin on acetylsalicylic acid-induced kidney and testis damage. Hum Exp Toxicol 33(4):383-395. https://journals.sagepub.com/doi/abs/10.1177/0960327113506240

7. Alvarez JG, Touchstone JC, Blasco L et al (1987) Spontaneous lipid peroxidation and production of hydrogen peroxide and superoxide in human spermatozoa Superoxide dismutase as major enzyme protectant against oxygen toxicity. J Androl 8(5):338-348. https://onlinelibrary.wiley.com/doi/abs/ 10.1002/j.1939-4640.1987.tb00973.x

8. Arisha SM (2017) Effect of grape seed extract, Gervital, against methotrexate induced histological and ultrastructural alterations in testes of albino rats. World J Pharm Res 6(7):98-126. https://wjpr.s3.ap-south-1.amazonaws.com/article_issue/1498804823.pdf

9. Ateşşahin A, Şahna E, Türk G et al (2006) Chemoprotective effect of melatonin against cisplatin-induced testicular toxicity in rats. J Pineal Res 41(1), 21-27. https://onlinelibrary.wiley.com/doi/abs/10.1111/j.1600-079X.2006.00327.x

10. Bagchi D, Ray S, Patel D et al (2001) Protection against drug-and chemical-induced multiorgan toxicity by a novel IH636 grape seed proanthocyanidin extract. Drugs Exp Clin Res 27(1):3-15. https://europepmc.org/article/med/11276828

11. Bain JM, Mercer F (1966) Subcellular organization of the developing cotyledons of Pisum sativum L. Aust J Biol Sci 19(1):49-68. https://www.publish.csiro.au/BI/BI9660049

12. Bancroft JD, Gamble M (2008) Theory and practice of histological techniques: Elsevier health sciences.https://books.google.com/books? $\mathrm{hl}=\mathrm{ar} \& \mathrm{l}=\& \mathrm{id}=\mathrm{CERPD}$ AAQBAJ\&oi=fnd\&pg=PP1\&dq=Bancroft,+John+D,+and+Marilyn+Gamble+2008\%09

Theory+and+practice+of+histological+techniques:+Elsevier+health+sciences.\&ots=ytXMqltoNQ\&sig=XxTx ALWNwukuvupdjCVIBnwOuQw

13. Belhan S, Özkaraca M, Kandemir FM et al (2017) Effectiveness of hesperidin on methotrexate-induced testicular toxicity in rats. Membr Biol 23(5):779-786. https://www.researchgate.net/profile/Fatih-Kandemir/publication/318311623_Effectiveness_of_Hesperidin_on_MethotrexateInduced_Testicular_toxicity_in_rats/links/59628325a6fdccc9b1488f33/Effectiveness-of-Hesperidin-on-Methotrexate-Induced-Testiculartoxicity-in-rats.pdf

14. Bergasa NV (2022) ) Autoimmune Hepatitis. Clinical Cases in Hepatology. Springer, 85-122. https://link.springer.com/chapter/10.1007/978-14471-4715-2_4

15. Bhattacharya S (2015) Reactive oxygen species and cellular defense system. Free radicals in human health and disease. Pp. 17-29: Springer. https://link.springer.com/chapter/10.1007/978-81-322-2035-0_2

16. Bozzola JJ, Russell LD (1999) Electron microscopy: principles and techniques for biologists: Jones \& Bartlett Learning https://books.google.com/books?

$\mathrm{hl}=\mathrm{ar} \& \mathrm{lr}=\& \mathrm{id}=\mathrm{zMkBAPACbEkC \& oi=fnd \& pg=PR21 \& dq=Bozzola},+J o h n+J,+a n d+L o n n i e+D e e+R u s s e l l+1999+E l e c t r o n+m i c r o s c o p y:$

+principles+and+techniques+for+biologists:+Jones+\%26+Bartlett+Learning.\&ots=AdNVWmmFK4\&sig=7ff0R-_uh_q6EKwJyZoKEp7rm5E

17. Claiborne A (1985) Handbook of methods for oxygen radical research. CRC Press, Florida, pp 283-284

18. El-Ashmawy IM, Gad SB, Salama OM (2010) Grape seed extract prevents azathioprine toxicity in rats. Phytother Res 24(11):1710-1715. https://onlinelibrary.wiley.com/doi/abs/10.1002/ptr.3200

19. Elelaimy I, Elfiky S, Hassan A et al (2012) Genotoxicity of anticancer drug azathioprine (Imuran): role of omega-3 ( $\omega$-3) oil as protective agent. J App Pharm Sci 2(4):14-23. http://www.japsonline.com/admin/php/uploads/421_pdf.pdf

20. Granados-Principal S, Quiles JL, Ramirez-Tortosa CL et al (2010) New advances in molecular mechanisms and the prevention of adriamycin toxicity by antioxidant nutrients. Food Chem Toxicol 48(6):1425-1438.

Page $7 / 12$ 
https://www.sciencedirect.com/science/article/pii/S0278691510002218

21. Hajizadeh Z, Soleimani Mehranjani M, Najafi G et al (2016) Black grape seed extract modulates fluoxetine-induced oxidative stress and cytotoxicity in the mouse testis.Jundishapur J Nat. Pharm Prod11(2). https://sites.kowsarpub.com/jjnpp/articles/18430.html

22. Hasanuzzaman M, Bhuyan M, Zulfiqar F et al (2020) Reactive oxygen species and antioxidant defense in plants under abiotic stress: Revisiting the crucial role of a universal defense regulator. Antioxidants 9(8):681. https://www.mdpi.com/783108

23. Hovnanyan K, Mamikonyan V, Margaryan A et al (2014) Antioxidants as effective remedies at hepatotoxic action of carbon tetrachloride. J Biochem. Biophys 2014. https://www.scirp.org/html/1-7100195_41999.htm

24. Hui WE, Li YZ, Fang PG et al (2020) Grape Seed Procyanidin Extract Attenuate Sodium Fluoride-induced Oxidative Damage and Apoptosis in Rat Kidneys. Biomed Environ Sci 33(6):454-457. http://www.besjournal.com/fileSWYXYHJKX/journal/article/swyxyhjkx/2020/6/PDF/19278.pdf

25. Karawya FS, El-Nahas AF (2006) The protective effect of vitamin C on Azathioprine induced seminiferous tubular structural changes and cytogenetic toxicity in albino rats. Cancer Ther 4:125-134. https://www.academia.edu/download/51078224/The_protective_effect_of_vitamin_C_on_Az20161227-1274-18vkpy7.pdf

26. Kumar AS, Deepthi KB, Prasad MDV et al (2011) Evaluation of the protective effects of omega-3 fatty acids against methotrexate induced testicular toxicity in male albino mice. Int J Phytopharm 2(2):48-52. https://citeseerx.ist.psu.edu/viewdoc/download?doi=10.1.1.1065 $.5949 \&$ rep=rep $1 \&$ type $=p d f$

27. Kwatra B (2020) A review on potential properties and therapeutic applications of grape seed extract. World J Pharm Res 9:2519-2540. https://www.researchgate.net/profile/Bharat-

Kwatra/publication/341134392_A_REVIEW_ON_POTENTIAL_PROPERTIES_AND_THERAPEUTIC_APPLICATIONS_OF_GRAPE_SEED_EXTRACT/ links/5eb06afa45851592d6b8c451/A-REVIEW-ON-POTENTIAL-PROPERTIES-AND-THERAPEUTIC-APPLICATIONS-OF-GRAPE-SEEDEXTRACT.pdf

28. Liu Z, Sun Y, Su L (2015) Effects of cisplatin on testicular enzymes and Sertoli cell function in rats. Fundamental Toxicological Sciences 2(4):137-145. https://www.jstage.jst.go.jp/article/fts/2/4/2_137/_article/-char/ja/

29. Maremanda KP, Jena G (2017) Methotrexate-induced germ cell toxicity and the important role of zinc and SOD1: Investigation of molecular mechanisms. Biochem Biophys Res Commun 483(1):596-601. https://www.sciencedirect.com/science/article/pii/S0006291X16321416

30. Marklund S, Marklund G (1974) Involvement of the superoxide anion radical in the autoxidation of pyrogallol and a convenient assay for superoxide dismutase. Eur J Biochem 47(3):469-474. https://febs.onlinelibrary.wiley.com/doi/abs/ 10.1111/j.1432-1033.1974.tb03714.x

31. Maruyama Y, Aoki N, Suzuki Y et al (1987) Sex-steroid-binding plasma protein (SBP), testosterone, oestradiol and dehydroepiandrosterone (DHEA) in prepuberty and puberty. Eur J Endocrinol 114(1):60-67. https://eje.bioscientifica.com/view/journals/eje/114/1/acta_114_1_009.xml

32. Mohamadpour M, Mollajani R, Sarabandi F et al (2020) Protective Effect of Grape Seed Extract on Dexamethasone-Induced Testicular Toxicity in Mice. Crescent J Med Biol Sci 7(1):59-65. http://eprints.bmsu.ac.ir/9068/

33. Onanuga IO, Ibrahim RB, Amin A et al (2014) Evaluation of the effects of ascorbic acid on azathioprine-induced alteration in the testes of adult Wistar rats. Int j biol chem sci 8(2):426-433. https://www.ajol.info/index.php/ijbcs/article/view/107045

34. Padmanabhan S, Tripathi D, Vikram A et al (2009) Methotrexate-induced cytotoxicity and genotoxicity in germ cells of mice: intervention of folic and folinic acid. Mutat Res Genet Toxicol Environ Mutagen 673(1):43-52. https://www.sciencedirect.com/science/article/pii/S1383571808003616

35. Patel N, Ghodasara D, Pandey S et al (2014) Subacute toxicopathological studies of methotrexate in Wistar rats. Vet World 7(7). http://citeseerx.ist.psu.edu/viewdoc/download?doi=10.1.1.587.1840\&rep=rep1\&type=pdf

36. Prahalathan C, Selvakumar E, Varalakshmi $P$ (2004) Remedial effect of DL-a-lipoic acid against adriamycin induced testicular lipid peroxidation. Molecular and cellular biochemistry 267, 209-214. https://link.springer.com/article/10.1023/B:MCBI.0000049385.13773.23

37. Priyadarshi R, Riahi Z, Rhim J-W (2022) Antioxidant pectin/pullulan edible coating incorporated with Vitis vinifera grape seed extract for extending the shelf life of peanuts. Postharvest Biol Technol 183:111740. https://www.sciencedirect.com/science/article/pii/S0925521421002799

38. Raja W, Dubey A, Verma P (2020) Evaluation of phytochemicals screening and antioxidant activity of vitis vinifera (grapes) fruit extract using fenton reaction. Eur J Biomed 7(7):582-587. https://www.researchgate.net/profile/Wasim-Raja-

2/publication/344298218_Evaluation_of_Phytochemicals_Screening_and_Antioxidant_Activity_of_Vitis_Vinifera_Grapes_Fruit _Extract_using_Fenton_Reaction/links/5f648b8492851c14bc841130/Evaluation-of-Phytochemicals-Screening-and -Antioxidant-Activity-of-Vitis-Vinifera-Grapes-Fruit-Extract-using-Fenton-Reaction.pdf

39. Ramadan BK, Schaalan MF, Mahmoud ES( (2018) Protective effect of taurine on thiopurine-induced testicular atrophy in male albino rats.J Steroids Horm Sci9(192). https://m.23michael.com/open-access/protective-effect-of-taurine-on-thiopurineinduced-testicular-atrophy-inmalealbino-rats-2157-7536-1000192.pdf 
40. Rao M, Blane K, Zonneberg M (1985) PC-STAT, one and two way analysis of variance. UGA Version 1A (C) copyright

41. Reggio A, Spada F, Rosina M et al (2019) The immunosuppressant drug azathioprine restrains adipogenesis of muscle Fibro/Adipogenic Progenitors from dystrophic mice by affecting AKT signaling. Sci Rep 9(1):1-13. https://www.nature.com/articles/s41598-019-39538-y

42. Richburg JH (2000) The relevance of spontaneous-and chemically-induced alterations in testicular germ cell apoptosis to toxicology. Toxicol Lett 112:79-86. https://www.sciencedirect.com/science/article/pii/S0378427499002532

43. Sedlak J, Lindsay RH (1968) Estimation of total, protein-bound, and nonprotein sulfhydryl groups in tissue with Ellman's reagent. Anal Biochem 25:192-120. https://www.researchgate.net/file.PostFileLoader.html?id=56cba9af6307d91d 708b4567\&assetKey=AS\%3A332089951047681\%401456187822637

44. Shaikh SP, Kumar H, Ali A et al (2020b) Ameliorative Effect of Zinc Chloride in Azathioprine Induced Reduction in Body and Testes Weight in Albino Rats. JSMC. http://jsmc.pk/index.php/jsmc/article/view/322

45. Shaikh S, Mohiuddin M, Kumar H et al (2020a) Protective effects of zinc chloride on azathioprine-induced toxicity on germinal epithelium of albino rats: A morphometric study. Pak J Surg 36:83-89. https://www.pjs.com.pk/journal_pdfs/jan_mar20/83.pdf

46. Shrestha S, Dhungel S, Saxena A et al (2007) Effect of methotrexate (MTX) administration on spermatogenesis: an experimental on animal model. Nepal Med Coll J 9:230-233. https://www.nmcth.edu/images/gallery/Editorial/Ry8oPs_shrestha.pdf

47. Zhang S, Ye C, Zhao W et al (2022) Product identification and toxicity change during oxidation of methotrexate by ferrate and permanganate in water. Front Environ Sci Eng 16:1-13. https://link.springer.com/article/ 10.1007/s11783-021-1501-8

48. Yucel Y, Oguz E, Kocarslan S et al (2017) The effects of lycopene on methotrexate-induced liver injury in rats. Bratisl Lek Listy 118(4):212216. https://avesis.medeniyet.edu.tr/yayin/ac33f305-3a8f-4280-b487-f4e07de7bc7d/the-effects-of-lycopene-on-methotrexate-induced-liverinjury-in-rats/document.pdf

49. Yüncü M, Bükücü N, Bayat N et al (2019) Protective Effect of Proanthocyanidin against Methotrexate-Induced Testicle Damage in Rats. Eur J Ther 25(1):51-57. https://www.researchsquare.com/article/rs-10900/latest.pdf

\section{Figures}

\section{Figure 1}

Percentage changes between initial and final body weights in control, gervital (GSE), methotrexate (MTX), azathioprine (AZA), gervital plus methotrexate (GSE + MTX) and gervital plus azathioprine (GSE + AZA) groups.

Values with different superscript letters are considered significantly different $(P<0.05)$.

\section{a Significantly different from control at $p<0.05$.}

\section{b,c not significantly different from control at $p<0.05$.}

\section{Figure 2}

Changes in testes relative weights in control, gervital (GSE), methotrexate (MTX), azathioprine, gervital plus methotrexate (GSE + MTX) and gervital plus azathioprine (GSE + AZA) groups.

Values with different superscript letters are considered significantly different $(P<0.05)$.

\section{a Significantly different from control at $p<0.05$.}

${ }^{b, C}$ not significantly different from control at $p<0.05$. 


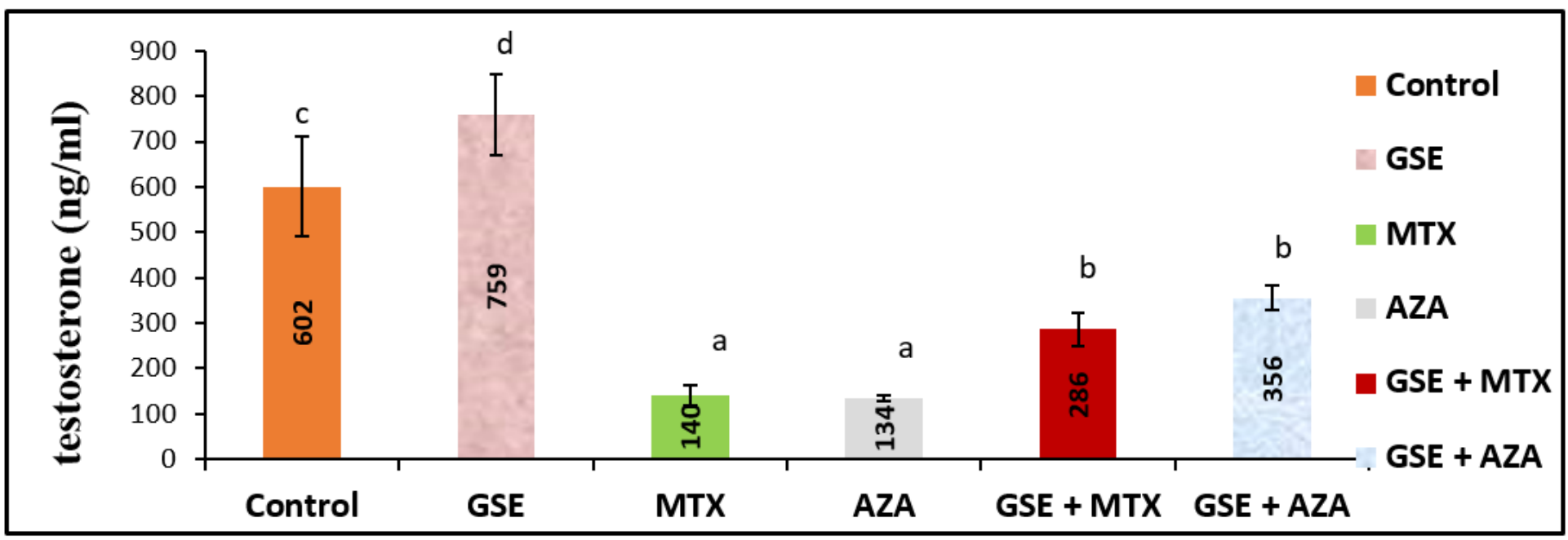

Figure 3

Changes in testosterone in control, gervital (GSE), methotrexate (MTX), azathioprine (AZA), gervital plus methotrexate (GSE + MTX) and gervital plus azathioprine (GSE + AZA) groups.

Values with different superscript letters are considered significantly different $(P<0.05)$.

a Significantly different from control at $p<0.05$.

${ }^{b}$ not significantly different from control at $p<0.05$.

Figure 4

(a \& b) and (c \& d): A Photomicrograph of testis sections of control rats revealing (a \& c): Normal seminiferous tubules (arrow) with active spermatogenesis and Spermatogonia (SG) resting upon the basement membrane. Interstitial tissue containing Leydig cell (LC) and a cluster of spermatozoa (SP) in the lumen (Lu) is seen. Scale bare $=100 \mu \mathrm{m}$. (b \& d): High magnification showing Primary spermatocytes (PS), recognized by their large nuclei containing coarse clumps of chromatin. Spermatids (SD) with rounded nuclei and spermatozoa (SP) were observed. Triangular Sertoli cell (SC) and spermatogonia (SG) at the basement membrane and the interstitial tissue containing Leydig cell (LC) are seen. Scale bare $=50$ $\mu \mathrm{m}$.

(e): A Photomicrograph of testis sections of rats treated with methotrexate showing: Severe degenerated and variable-sized seminiferous tubules (thin arrow), where many tubules appeared with a marked decrease in the spermatogenic cells and few or no sperms. Detachment of spermatogenic cells from the basal lamina (arrowhead) and vacuolated cytoplasm (V) and notice sloughing of spermatogenic cells into the lumen of seminiferous tubules (thick arrow). Scale bare $=200 \mu \mathrm{m}$.

(f): A Photomicrograph of testis sections of rats treated with azathioprine revealing: Degenerated seminiferous tubules with ruptured basement membrane $\left(^{*}\right)$ are observed. Notice the detachment of spermatogenic cells from the basal lamina (arrowhead) and vacuolated cytoplasm (V). Reduction of spermatogenic cells, pyknosis of some nuclei (arrow) are also observed. Interstitial tissue (IT) containing degenerated Leydig cell (LC) Scale bare $=100 \mu \mathrm{m}$.

(g): A Photomicrograph of testis sections of rats treated with methotrexate and gervital showing: Approximate recovery of seminiferous tubules. Amelioration of spermatogenic cells and spermatozoa (SP) except a few vacuoles (V) and normal Leydig cells are seen. Scale bare $=200 \mu \mathrm{m}$.

(h): A Photomicrograph of testis sections of rats treated with azathioprine plus gervital revealing: Improvement of spermatogenesis and nearly normal structure in most seminiferous tubules. Compact spermatogenic layers with few degenerative germ cells, except a few vacuoles ( $V$ ) and normal Leydig cells (LC). Scale bare $=100 \mu \mathrm{m}$.

Figure 5 
(a-d): Electron micrograph of a portion of a seminiferous tubule of control testis showing (a): The spermatogonia (SG) resting on the basement membrane (BM), myoid cell (MC), the Sertoli cell (SC) having a triangular nucleus and primary spermatocyte (PS) with mitochondria (M) and large spherical nucleus. Scale bare $=2 \mu \mathrm{m}$. b): Normal looking early rounded spermatid (SD) with spherical nuclei, acrosomal cap (AC), and peripherally located mitochondria (M). Scale bare $=2 \mu \mathrm{m}$. c): Lumen ( $\mathrm{Lu})$ contains normal spermatozoan (SP) at the mid piece and tail region. Scale bare $=2 \mu \mathrm{m}$. d): Normal interstitial tissue containing Leydig cell (LC) with large nucleus ( $\mathrm{N}$ ), thin rim of chromatin, prominent nucleolus, lipid droplet (Li), and capillaries were observed. Scale bare $=2 \mu \mathrm{m}$.

\section{Figure 6}

(a-d): Electron micrograph of a portion of a seminiferous tubule of Testis treated with methotrexate showing (a): Many vacuoles (V), vacuolated mitochondria (M) in addition to the presence of some lysosome (LY) in spermatogonia (SG), Sertoli cell (SC) and primary spermatocyte (PS). Scale bare $=2 \mu \mathrm{m}$. b): Distorted spermatid (SD) with marked cytoplasmic vacuolation $(\mathrm{V})$ and rarified cytoplasm surrounded with the large lytic area $\left({ }^{\star}\right)$. Notice the presence of some lysosome (LY) and some degenerated mitochondria (M). Scale bare $=2 \mu \mathrm{m}$. $\mathbf{c})$ : Marked decrease in the number of sperms (SP) in the lumen (Lu) of the seminiferous tubule. Scale bare $=2 \mu \mathrm{m}$. d): Degenerated Leydig (LC) cell with irregular nucleus (N), a thick rim of heterochromatin, few lipid droplets $(\mathrm{Li})$, and dilated smooth endoplasmic reticulum (arrow) was also observed. Scale bare $=2 \mu \mathrm{m}$.

\section{Figure 7}

(a-e): Electron micrograph of a portion of a seminiferous tubule of Testis treated with azathioprine showing: a): Degenerated Sertoli (SC) cells and spermatogonia cells (SG) with many vacuoles (V) and an overall decrease in cytoplasmic ground substance. Scale bare $=2 \mu \mathrm{m}$. $\mathbf{b}$ ): Thick irregular basement membrane (BM). Vacuolated (V) primary spermatocyte (PS) and severe degenerated Sertoli cells (SC) with many vacuoles (V) and many lysosomes (LY) were seen. Scale bare $=2 \mu \mathrm{m} . \mathrm{c})$ : Degenerated and vacuolated (V) spermatid (SD). Notice the dissolution of some cells (D). Scale bare $=2 \mu \mathrm{m}$. d): Abnormal spermatid (SD) with vacuolated cytoplasm (V), degenerated nucleus, and some lysosomes (LY) in addition to an obvious decrease in the number of sperms (SP) in the lumen (Lu). Scale bare $=2 \mu \mathrm{m}$. e): Abnormal interstitial tissue with degenerated Leydig cell (LC) its nucleus $(\mathrm{N})$ with dark clumps of heterochromatin and presence of few lysosomes (LY). Scale bare $=2 \mu \mathrm{m}$.

\section{Figure 8}

(a-d): Electron micrograph of a portion of a seminiferous tubule of Testis treated with methotrexate plus gervital showing: a): Amelioration in the structure of spermatogonium (SG), Sertoli cell (SC), and primary spermatocyte (PS) except few degenerated mitochondrial $(\mathrm{M})$. Scale bare $=2 \mu \mathrm{m}$. b): Normally rounded spermatid (SD) with a rounded nucleus and peripherally located mitochondria (M) except few cytoplasmic vacuolations (V) and few lysosomes. Scale bare $=2 \mu \mathrm{m}$. c): Lumen $(\mathrm{Lu})$ with marked recovery in transverse sections of normal sperms (SP) at the mid piece and tail region. Scale bare $=2 \mu \mathrm{m}$. d): Normal interstitial tissue contained Leydig cells with a large nucleus (N), prominent nucleolus, smooth endoplasmic reticulum, lipid droplets $(\mathrm{Li})$, and blood capillaries $(\mathrm{C})$. Scale bare $=2 \mu \mathrm{m}$.

\section{Figure 9}

(a-d): Electron micrograph of a portion of a seminiferous tubule of testis treated with azathioprine plus gervital showing: a) Slightly normal basement membrane (BM), improvement in the structure of cells except vacuolation in Sertoli cell (SC), spermatogonia (SG), primary spermatocyte and spermatid (SD) which with a rounded nucleus and normal acrosomal cap $(A C)$. Scale bare $=2 \mu$ m. b) Normal-looking early rounded Spermatid $(\mathrm{SD})$ with a rounded nucleus, acrosomal cap $(\mathrm{AC})$, and peripherally located mitochondria $(\mathrm{M})$ with few cytoplasmic vacuolation $(\mathrm{V})$. Scale bare $=$ $2 \mu \mathrm{m}$. c) Spermatid and a moderate number of cross sections at mid piece and tail region of sperms (SP) in the lumen (LU). Scale bare $=2 \mu \mathrm{m}$. $d)$ Interstitial tissue and Leydig cell with normal nucleus $(\mathrm{N})$ and a moderate number of lipid droplets $(\mathrm{Li})$. Scale bare $=2 \mu \mathrm{m}$.

\section{Supplementary Files}


This is a list of supplementary files associated with this preprint. Click to download.

- GraphicalAbstract.png

Page 12/12 